\title{
Thermodynamic Phase Numerical Simulation of Torsion Beam based on LS-DYNA
}

\author{
Kai $Y U^{1,2, a}$, Fei XIONG ${ }^{1,2, b,{ }^{*}}$ and Kai LIU ${ }^{2, c}$ \\ ${ }^{1}$ School of MaterialsScience and Engineering, Hefei University of Technology, Hefei 230009, China \\ ${ }^{2}$ Lightweight Technology, Geely Automobile Research Institute, Hangzhou 311228, China \\ ayukai040310@163.com, bxiongfei@geely.com, 'Cliukai7@geely.com
}

Keywords:Thermal mechanical coupling, Hot stamping, Cooling rate, Martensite

\begin{abstract}
In order to study the temperature field, stress field, strain field, thinning rate and phase distribution in the hot forming process of torsion beam, the thermal mechanical coupling numerical simulation method based on LS-DYNA is adopted in this paper. Study found: Due to the different regions of part contact with the mould in the different order, the maximum principal strain area in the highest temperature region, the maximum principal stress area is located in the lower temperature region; In hot forming, the highest content of ferrite, pearlite and bainite are all less than $1 \%$. After the end of hot stamping, austenite is mainly distributed in the highest temperature region, and the content is $22.32 \%$, martensite is mainly distributed in the lowest temperature, and the content is $98.22 \%$.
\end{abstract}

\section{Introduction}

Torsion beam is an important part of car rear suspension. The design of strength, stiffness and fatigue strength is the key point of the whole rear suspension system. Typical torsion beam assembly is mainly composed of five parts. Torsion beam is used to withstand the main vertical and lateral torsional moment. Trailing arm is welded on the left and right sides of the torsion beam. Shaft sleeve tube is decorated in the front of trailing arm is used to connect body. The spring bracket and wheel bracket, etc whose function mainly is vibration, vibration absorber and the wheel orientation.

Torsion beam structure not only has an important influence on the strength and stiffness of the parts, and the weight of different structure is different.At present, there are 4 main types of torsion beam structure: V-shaped torsion beam, H-shaped torsion beam, semi-circular arc torsion beam and the pipe by mechanical pressing forming for closed section of the torsion beam. In order to meet the needs of space and load, the torsion beam is designed as a hollow variable cross-section, which can improve the overall strength, stiffness and bending modulus of the parts, and greatly reduce the weight of the parts.

Under the background of lightweight of auto, the hydro forming torsion beam has great advantages in terms of weight loss, or bending modulus of the section. The United States, Germany, Japan, South Korea's automobile industry has adopted a large number of hydro forming torsion beam. But the original tensile strength of the material is no more than $700 \mathrm{MPa}$, and with the increase of the strength of the material, the spring back increases, and the forming precision is hard to guarantee. Compared with that, the hot forming can overcome the high strength, low ductility, large deformation resistance, easy to break and so on. Hot forming with high strength steel 22MnB5 through the mold quenching technology to form a full martensite microstructure, tensile strength of up to $1500 \mathrm{MPa}$, parts almost no rebound.

Compared with the traditional cold forming process, the hot forming process is characterized by a constant temperature field in the forming process. Under the effect of temperature field, the microstructure and mechanical properties of the sheet are changed. This leads to the change of the stress field of the sheet metal and at same time, the reaction of the stress field of the sheet metal have an adverse effect on the temperature field of sheet metal. So hot molding process involves three coupling effect which include temperature field, stress field and phase transformation. 
In this paper, the distribution of temperature field, phase distribution, stress field and strain field in the hot forming process of torsion beam are studied by the numerical simulation. The research results will pave the way for the optimization of the experimental process by analyzing the distribution of martensite, cooling rate, temperature distribution, thinning rate and forming precision.

\section{Materials and Parts}

\section{Material Properties}

Currently the world's most widely used hot forming material is 22MnB5 (USIBOR1500) developed by the world's largest Steel Corp Acelor. Its main chemical composition is shown in table 1. The initial microstructure of the material is ferrite and pearlite, the yield strength and tensile strength arerespectively 370MPa and 510MPa. However, after hot forming, the microstructure of the parts is martensite, the mechanical properties increase greatly, the yield strength and tensile strength reach $1250 \mathrm{MPa}$ and 1600MPa respectively, and have good impact toughness

Table 1. 22MnB5 chemical composition

\begin{tabular}{llllllll}
\hline Element & C & Si & Mn & S & Al & B & Cr \\
\hline minimum value & 0.220 & 0.200 & 1.200 & - & 0.020 & 0.002 & 0.110 \\
maximum value & 0.250 & 0.300 & 1.400 & 0.005 & 0.050 & 0.005 & 0.200 \\
\hline
\end{tabular}

In the process of hot forming, the temperature change is very violent, and its influence on the related properties of the material cannot be ignored. In this paper, the heat transfer coefficient and specific heat of the material are important parameters in the process of hot forming.

\section{Part Shape Features}

The shape of the torsion beam part studied in this paper is shown in Fig.1. As shown in Fig.1, along the axis of the part, the expansion rate of the $\mathrm{A}, \mathrm{B}$, and $\mathrm{C}$ cross section is not the same. Among them, the expansion rate of $\mathrm{A}$ and $\mathrm{C}$ section is bigger. The diameter of the original tube is $89.5 \mathrm{~mm}$ and the thickness is $3.5 \mathrm{~mm}$. The " $\mathrm{C}$ " is the maximum cross section and the width is $110 \mathrm{~mm}$; the " $\mathrm{A}$ " is the minimum cross section and the width is $84 \mathrm{~mm}$.

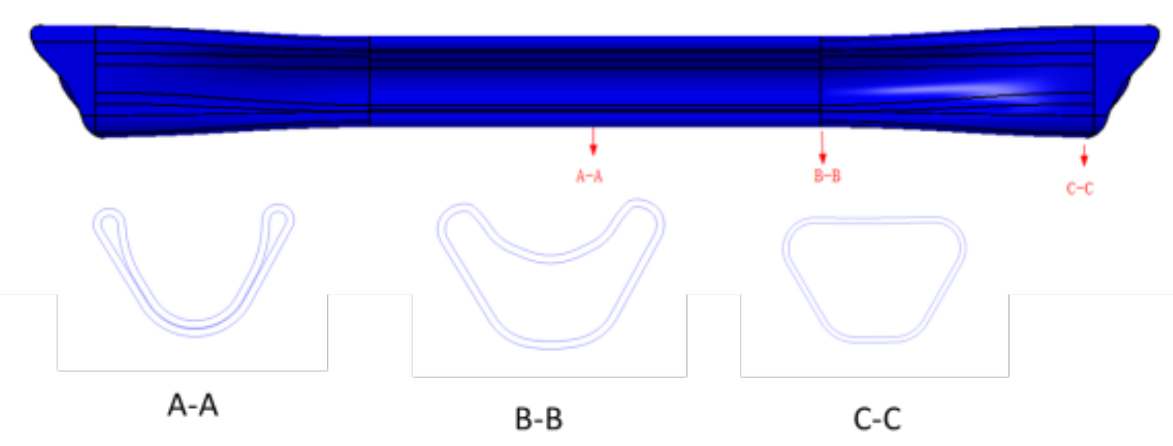

Fig.1Torsion beam part drawing and typical section shape

\section{Finite Element Model and Simulation Program}

\section{Finite Element Simulation Software and Related Settings}

In this paper, the finite element simulation software is LS-DYNA, post-processing uses the LS-prepost output of the cloud. The establishment of thermal coupling is mainly related to physical 
properties, rheological behavior, boundary condition and element model. In this paper, we use MAT244 material for the torsion beam. In the calculation process, the adaptive grid algorithm is adopted and the contact between blank and die surface is defined as face to face which is *CONTACT_FORMING_ONE_WAY_SURFACE_TO_SURFACE_THERMAL. The coefficient of friction between the mould and the blank is defined as 0.5 and thermal contact resistance is set to constant $4000 \mathrm{~W} / \mathrm{m} 2 \mathrm{~K}$. The initial thickness of the tube blank is $3.5 \mathrm{~mm}$, and the initial temperature is $1073 \mathrm{~K}$. In the initial stage of hot forming, the contact between the mould and the billet leads to the temperature rise, but the cooling water channel is arranged inside the mould. So the temperature of the mould is approximately constant and set to 298K. During the hot forming process, the heat conduction between the billet and the mould is much larger than that of the heat convection and heat radiation. Therefore, the heat transfer coefficient and specific heat of the material are the important parameters of the heat forming. The thermal physical properties of the blank and the die are defined by *MAT_THERMAL_ISOTROPIC_TD_LC.

\section{Hot Forming Process}

There is a more process, which is blank heat process in hot forming than cold forming. The hot forming process is mainly divided into direct hot forming and indirect hot forming. These two kinds of hot forming each have their own advantages and disadvantages. Direct hot forming reduces the preform in the process of forming process, a pressure machine, the working procedure and the production cost. This process is mainly used for simple shape, small deformation of the parts. Indirect heat forming process is before heating blank is preformed to $90 \%$ of the parts of the final geometry by cold forming. This forming method is mainly used for the production of complex shapes, the billet deformation degree of parts. Therefore, multiplex step forming is adopted.

In this paper, the advantages of direct and indirect heat forming are set up by using a multi - step process. The cost, the forming difficulty, the production efficiency has the irreplaceable advantage. The lower the temperature of the tube during the transfer and forming process, the lower the flow of material in the forming process.The billet is heated to $1123 \mathrm{~K}$ in the heating furnace and the heat preservation time. Then the pipe was transported to eventually forming pressure machine, punch move $105 \mathrm{~mm}$ with $100 \mathrm{~mm} / \mathrm{s}$ speed and is prohibited. Meantime, on both sides of the punch at the speed of $300 \mathrm{~mm} / \mathrm{s}$ forward motion $150 \mathrm{~mm}$, then the ban does not move. At this time, the punch move $15 \mathrm{~mm}$ with $100 \mathrm{~mm} / \mathrm{s}$ speed, and realize the mould closing with quenching time more than $3 \mathrm{~s}$.

\section{Results and Analysis}

\section{Forming Analysis}

Fig. 2 shows the temperature field distribution in the tube blank during forming process. Before left and right sides hold clamping, tube billet V-shaped section first contact with the mould with first quenching and low temperature. (Fig.2.a) After that, with the expansion of the amount of the increase, more area began to contact with mould, the temperature of these region began to decline rapidly. After the quenching, the maximum temperature is $299^{\circ} \mathrm{C}$. (Fig.2.b) The lowest temperature is in the $\mathrm{V}$ shaped corner. This is because from forming at the beginning, these region contact with mould tightly with a long mould quenching time and temperature can drop quickly. The highest temperature is in the lugs of V-shaped section. Before mould clamping, these has not contacted with mould with air cooling condition. After mould clamping, these region start quenching, so the quenching time is the shortest, the temperature drop is the slowest, so after the forming, the temperature is the highest. After the hot forming, the highest temperature of the parts is $299^{\circ} \mathrm{C}$ and the cooling rate is $77^{\circ} \mathrm{C} / \mathrm{S}$ which is greater than the martensite critical cooling rate $30^{\circ} \mathrm{C}$.So it can occur martensite transformation. 


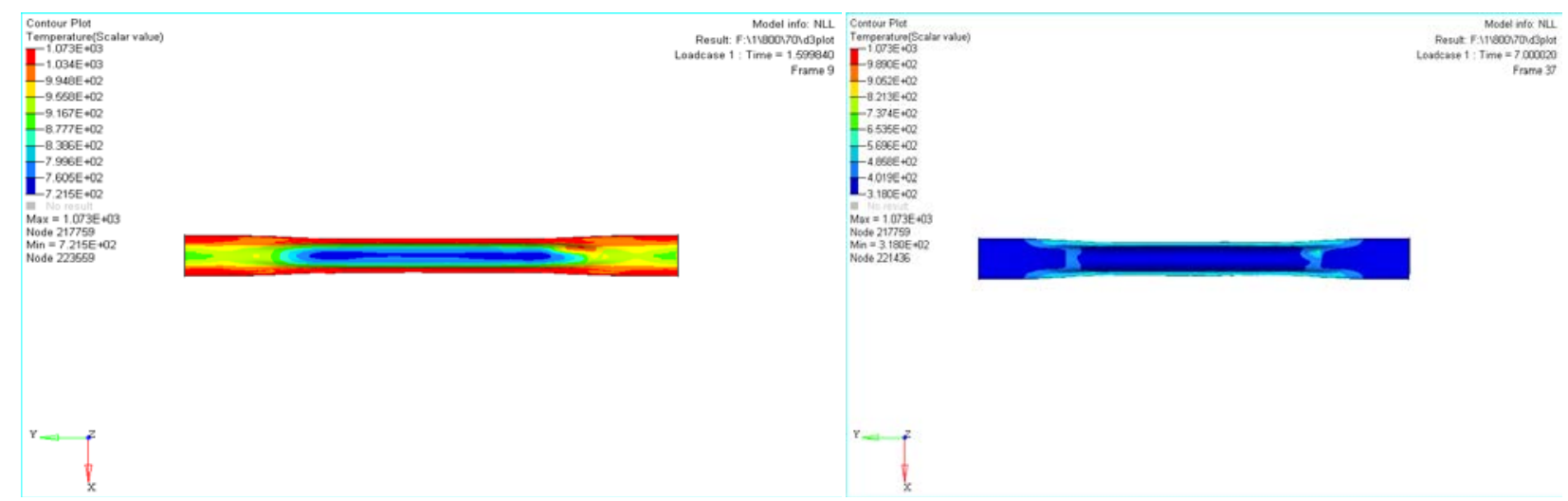

(a)Mould clamping-1.5s(b)End of quenching-7

Fig.2Temperature field distribution in forming process

The thickness change of tube after the end of the process is shown in Fig.3. Before mould clamping, the initial thickness of the tube is $3.5 \mathrm{~mm}$. After that, the minimum wall thickness is $3.274 \mathrm{~mm}$. The thinning rate is $6.49 \%$, less than $13 \%$ of the critical thinning rate of the hot forming and the minimum wall thickness is " $\mathrm{B}$ " section. Because the shape of this region is from the outer convex into the inner concave and deformation is huge; " $\mathrm{B}$ " section is in the transition section which is between " $\mathrm{A}$ " and "C" section, so the shape change dramatically, andthe material needs to flow on both sides.

The maximum principal stress and the maximum principal strain distribution of the torsion beam are shown in Fig.4 and Fig.5. e learn that the maximum principal strain is mainly distributed in the $\mathrm{B}$ section. The temperature of this area is the highest and the temperature drop is the slowest. At same time, the material flow is good, which is favorable for forming. The maximum stress region is in the lug of $\mathrm{C}$ section. This region first contact with the mould and the quenching time is the longest. Meantime, the temperature drop the fastest and the temperature is lowest, so the material mobility is poor that is not conducive to forming. In the forming process, the material hardening law of different regions is different, the maximum principal stress region and the maximum principal strain region are not the same, which is different from the cold forming.More importantly, the larger tensile stress region in the mode of quenching process to produce the quenching crack and the tendency of residual stress is greater, for the torsion beam parts, crack and residual stress will accelerate the fatigue damage. Therefore, in the actual production process, we need to ensure that the temperature uniformity and focus on the risk of the region.

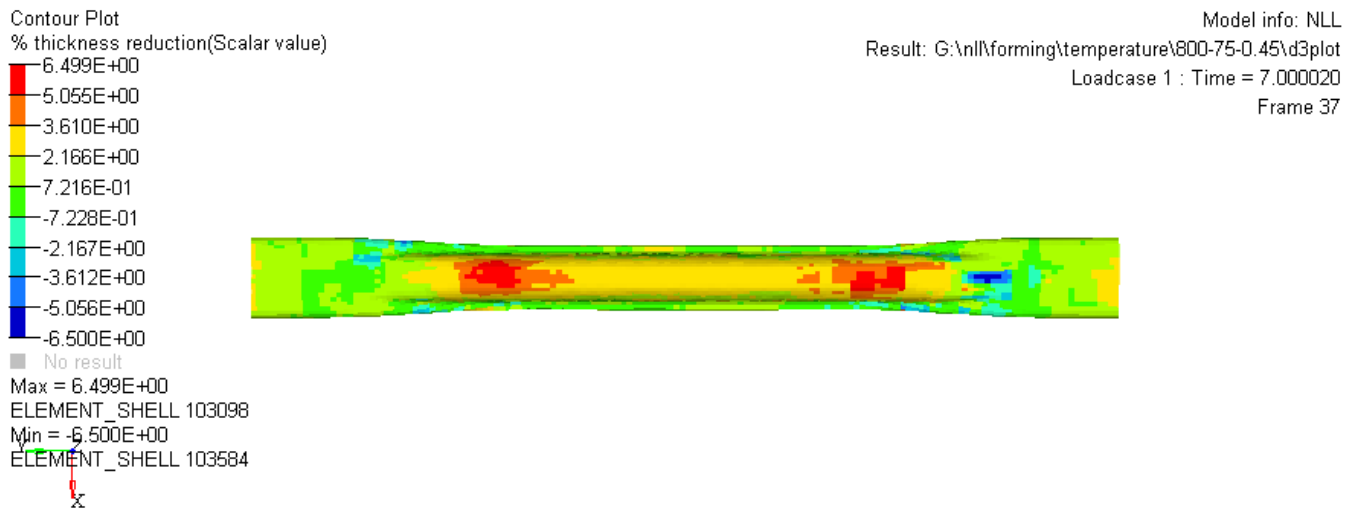

Fig.3Part thinning rate 


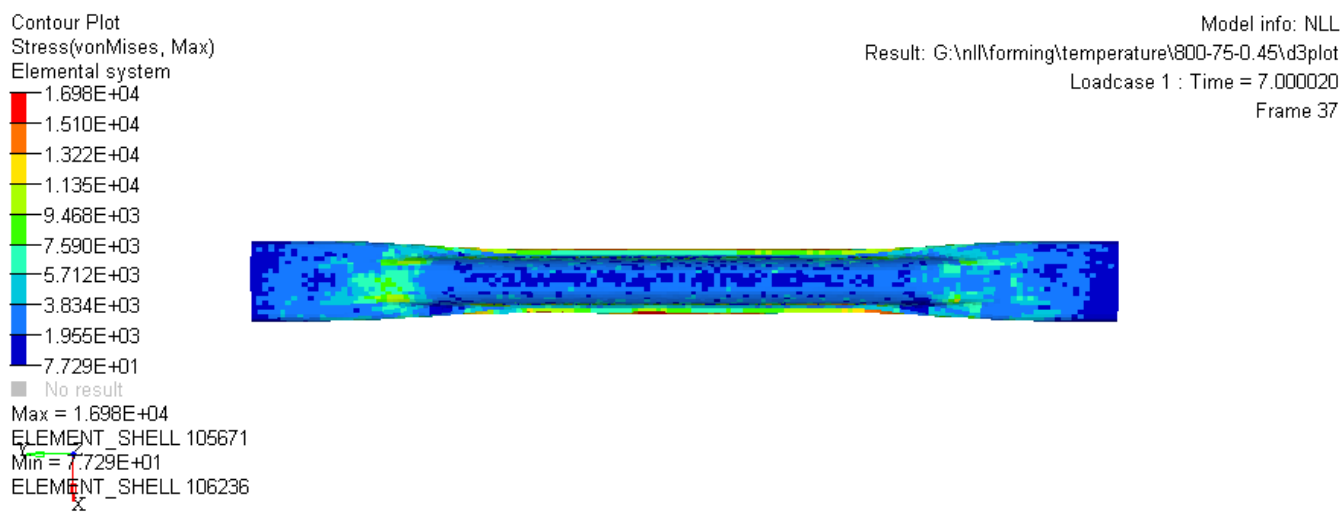

Fig.4Maximum principal stress distribution

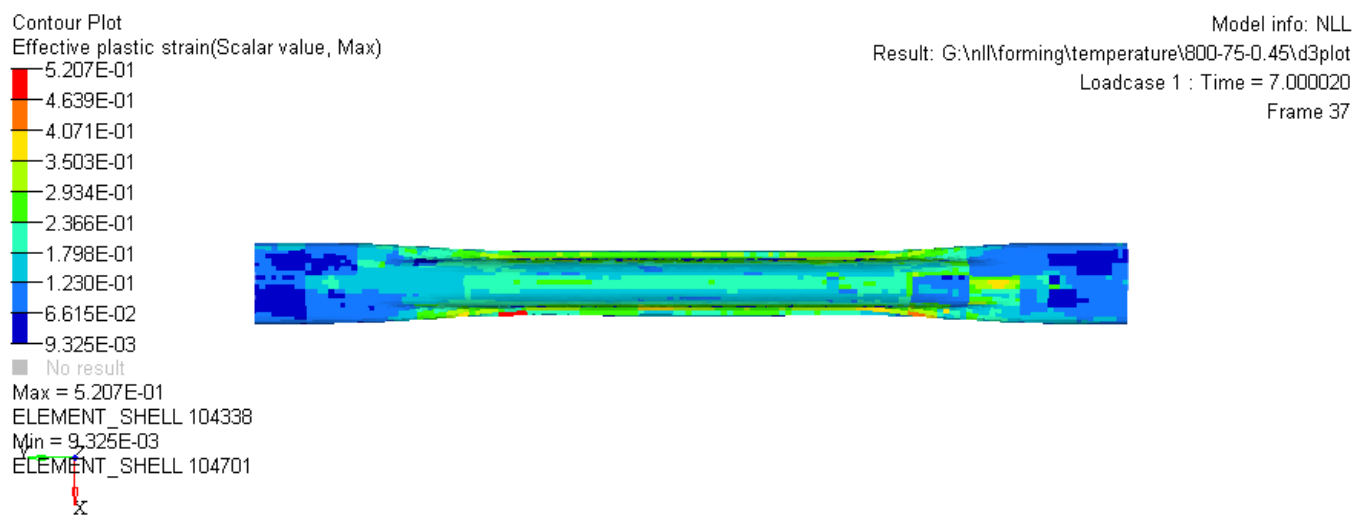

Fig.5Maximum principal strain distribution

\section{Phase Distribution}

After the hot forming, the distribution of austenite, bainite, ferrite and pearlite is shown in Fig.6. Ferrite, pearlite and bainite are all less than 1\%. Relatively ferrite is mainly distributed in two convex lugs of " $A$ " cross section. This is due to this region contact with mould last, mould quenching time is short. Pearlite distributed mainly in the " $C$ " section, because before two supporting clamping head closing, these regions is in the free condition with no boundary conditions. After clamping head closing, these regions contact with mould, so quenching is inadequate. Bainiteare mainly distributed in “B”section. After mould closing, hold head doesn't make the shape, size restrictions and these regions don't closely contact with the mould. So the area of the bainite transformation happened. The austenite is mainly distributed in the B section, the content is $22.32 \%$, which is also the highest temperature after forming; Relatively speaking, the minimum content of martensite is $77.6 \%$. The red area martensite content is relatively high and after forming the temperature is the lowest. The quenching time of these regions is long and the highest content is $98.22 \%$. 


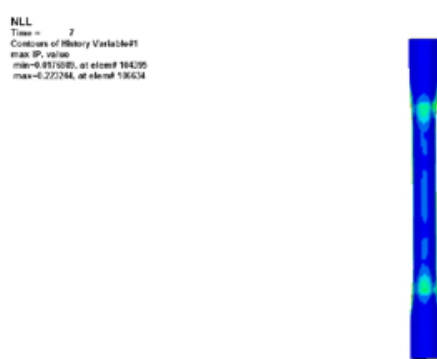

(a)Austenite

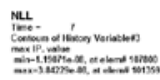

(c)Ferrite

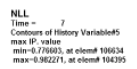

$L^{2}$

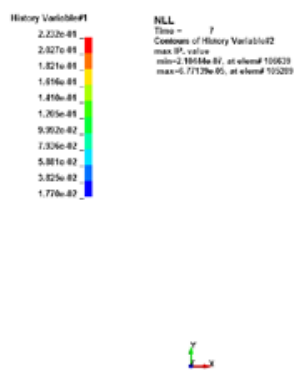

(b)Bainite

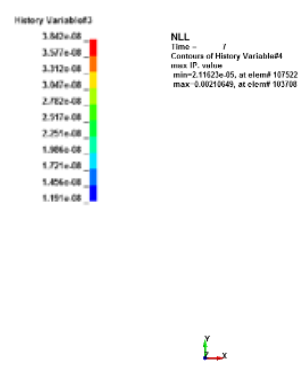

(c)Pearlite

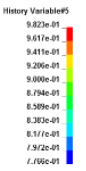

(e)Martensite

Fig.6 Phase distribution

\section{Conclusion}

1) Due to the good fluidity of the material during the hot forming process, the thinning rate of the tube is $6.49 \%$, and the maximum thinning is " $\mathrm{B}$ " section. These area is fed to both sides during the forming process;

2) Different regions of tube blank contact with mould in different sequence is different which result in the temperature distribution of different regions of the tube is different. The maximum principal stress region is different from the maximum principal strain region and the larger tensile stress region in the mode of quenching process to produce the quenching crack and the tendency of residual stress is greater;

3) After the hot forming, the highest temperature of the parts is $299^{\circ} \mathrm{C}$ and the cooling rate is $77^{\circ} \mathrm{C} / \mathrm{S}$ which is greater than the martensite critical cooling rate $30^{\circ} \mathrm{C}$.So it can occur martensite transformation;

4) After hot forming, torsion beams mainly contain austenite,bainite, ferrite and pearlite, and 
the highest content of ferrite, pearlite and bainite are all less than $1 \%$. The austenite is mainly distributed in the B section and the content is $22.49 \%$, but the content of martensite is $98.22 \%$.

\section{References}

[1]SNEIDER K, CHOIH, OH J,etal. High strength hydroformed automotive part developed by POSCO[C].Hydroforming of sheet-tubes and profiles. Fellbach: Mathias Liewald, 2008. 61-76;

[2] KYUNG T L, HONG J B. Tube hydroforming process design of torsion beam type rear suspension considering. Durability [J] International Journal of Modern Physics B, 2008, 22(31): 6199-6205;

[3] HAN C, YUAN S J. Reduction of friction and calibration pressure by section preform during hydroforming of tubular automotive structural components[J]. Advanced Materials Research, 2008, 44-46: 143-150;

[4] Kiese J. New Lightweight StellsFor Automobile Applications Potential and Risk [A]. Hashimoto S, Jansto S, Mohrbacher $\mathrm{H}$, el al eds. Proceedings of Internationals Conference on Niobium Microalloyed Sheet Steel for Automotive Applications[C]. Araxa MG, Brazil: 2005, 203-212.

[5] J. E. Morral and J. B. Cameron. Boron hardenability mechanisms[M]. the Metallurgical Society of the A. I. M. E. , Warrendale, USA, 1980.

[6] W. F. Jandeska and J. E. Morral. The distribution of boron in austenite[M]. Metallurgy Transactions.1972, 3(11): 2 933-2 937.

[7] D. A. Mortimer, M. G. Nicholas. Surface and grain-boundary energies of AISI 316 stainless steel in the presence of boron[J]. Metal Science. 1976(10): 326-332.

[8]Ming-Fu Li, Tzu-Shin Chiang, Jiun-Hau Tseng, Chia-Nung Tsai; Hot stamping of door impact beam[C] . 11th International Conference on Technology of Plasticity, ICTP 2014, 19-24 October 2014,Nagoya Congress Center, Nagoya, Japan

[9]Altan, T. Hot-stamping boron-alloyed steels forautomotive parts, part I: Process methods and uses.Stamping J. 2006: 4041. 